\title{
CONTRIBUICÕES DA SOCIOLOGIA PARA O ESTUDO DA DIVULGACÃO CIENTÍFICA NA INTERFACE CAMPO CIENTÍFICO E ESPAÇO ESCOLAR: UM OLHAR A PARTIR DO CONCEITO DE FRONTEIRA
}

\author{
GRACIELLA WATANABE ${ }^{*}$ \\ https://orcid.org/0000-0001-6710-0194 \\ MARCELO GAMEIRO MUNHOZ" ** \\ https://orcid.org//0000-0003-3695-3180 \\ MARIA REGINA KAWAMURA ${ }^{\| * *}$ \\ https://orcid.org/0000-0002-8842-9316
}

RESUMO: A investigação apresentada nesse artigo pretende discutir as potencialidades de se pensar a divulgação científica como prática elaborada nas aproximações entre campos e espaços sociais. Para tanto, pretende-se debater o conceito sociológico de fronteira como o lugar onde diferentes agentes sociais possam se aproximar e construir coletivamente espaços criativos. Dessa atividade compartilhada se reconhece a construção de práticas e sentidos cujo objetivo seja a negociação de ações de divulgar que se faça significativa para todos aqueles que participam dela, ou seja, cientistas, jornalistas, alunos, professores, público geral etc. Nesse contexto, se defende, através dos cientistas analisados, que a fronteira pode ser um instrumento importante para compreender como estão sendo tratadas, implicitamente, tais práticas e o desvelamento dos diferentes objetivos implícitos que delas emergem.

Palavras-chave: Divulgação científica. Fronteira. Teoria sociológica de campos.

\section{CONTRIBUCIONES SOCIOLÓGICAS AL ESTUDIO DE DIVULGACIÓN CIENTÍFICA SOBRE LA INTERFAZ DE CAMPO CIENTÍFICO Y EL ESPACIO ESCOLAR: UNA MIRADA AO CONCEPTO DE LA FRONTERA}

*Doutora, Universidade de
São Paulo. Professora, Universidade
Federal do ABC (UFABC). Grupo
Desigualdade Educacional, Ciência
e Democracia (DECiDe).
E-mail: < graciella.watanabe@ufabc.edu.br >
* *Doutor, Universidade de
São Paulo (USP). Professor,
Universidade de São Paulo.
High Energy Physics and
Instrumention Center (HEPIC).
E-mail: < munhoz@if.usp.br >
* * Doutora, Universidade de
São Paulo (USP). Professora,
Universidade de São Paulo.

RESUMEN: La investigación presentada en este artículo pretende discutir las potencialidades de pensar la divulgación científica como práctica elaborada en la aproximación entre campos y espacios sociales. Para ello,

\footnotetext{
I Universidade Federal do ABC, Santo André, SP - Brasil.

II Universidade de São Paulo, São Paulo, SP - Brasil.
} 
se pretende debatir el concepto sociológico de frontera como el lugar donde diferentes agentes sociales puedan acercarse y construir colectivamente espacios creativos. De esa actividad compartida se reconoce la construcción de prácticas y sentidos cuyo objetivo sea la negociación de acciones de divulgar que se haga significativa para todos aquellos que participan de ella, es decir, científicos, periodistas, alumnos, profesores, público general, etc. En este contexto, se defiende, a través de los científicos analizados, que la frontera puede ser un instrumento importante para comprender cómo se está tratando implícitamente tales prácticas y el desvelamiento de los diferentes objetivos implícitos que de ellos emergen.

Palabras-clave: Divulgación científica. Frontera. La teoría sociológica de los campos.

\section{CONTRIBUTIONS OF SOCIOLOGY TO THE STUDY OF THE SCIENCE PROPAGATION ON THE INTERFACE OF SCIENCE FIELD AND SCHOOL SPACE: AN UNDERSTANDING FROM THE CONCEPT OF BORDER}

ABSTRACT: The research presented in this article aims to discuss the potential of thinking about scientific propagation as a practice originated by the approximation between fields and social spaces. With this aim, it is intended the debate of the sociological concept of border as the place where different social agents can approach and collectively construct creative spaces. This shared activity recognizes the construction of practices and meanings with the purpose of negotiating actions to disseminate that is meaningful to all those who participate in it, ie scientists, journalists, students, teachers and general public. In this context, it is argued, through the scientists analyzed, that the border can be an important instrument to understand how these practices are being implicitly treated and the unveiling of the different implicit objectives that emerge from them.

Keywords: Scientific popularization. Border. Sociological field theory. 


\section{INTRODUĈ̣̃O}

Não é raro pesquisadores em ensino de física e áreas correlatas apontarem as dificuldades de definir o termo "divulgação científica" (GERMANO; KULESKA, 2007; SILVA,2006; RIBEIRO; KAWAMURA, 2006), seja pela complexidade de entendimentos ou sentidos que são negociados entre os atores sociais que a compõem, como a própria gênese de seu conhecimento interdisciplinar. Dentre os diferentes tipos de compreensões, se mobilizam métodos, processos de ensino-aprendizagem, interfaces com ações educacionais formais e perspectivas históricas que acabam por gerar dúvidas e entraves para o debate sobre o que é efetivamente a divulgação científica (DC).

Sob o ponto de vista educacional, trabalhos atuais vêm apontando a dimensão peculiar desses discursos onde os textos de DC são inseridos, por exemplo, nos livros didáticos como possibilidades de promover a contextualização dos conteúdos curriculares (SOUZA; ROCHA, 2018). Defende-se que tais inserções fazem-se necessárias para a prática de novos olhares para a ciência no ambiente escolar conforme apontam Schneider, Meglhioratti e Soares (2017) e visam a construção de novos sentidos, elaborados no confronto de diferentes áreas que permeiam a produção do saber científico. Para Martins, Nascimento e Abreu (2004) tal relação perpassa reconhecer as diferenças entre contextos, compreendendo, assim, que a DC ao adentrar o espaço escolar deve ser pensado sob suas distintas formas de produção do saber. Desse modo, os materiais provindos da DC se tornam um importante meio de promover no ambiente formal de educação a aprendizagem científica desde que reconhecendo suas especificidades e consequente necessidade de movimentos discursivos para a adaptação desses textos nas salas de aulas de ciências. Nesse linha, Silva e Almeida (2005) enfatizam a necessidade do uso de textos de DC para a sala de aula, fazendo coro ao debate de que educar em contextos formais não pode ser considerado uma extensão das práticas da divulgação científica, mas uma produção mobilizada pelos contextos e sentidos negociados no processo educativo. Lima e Giordan (2018) entendem, nesse contexto, que a divulgação científica ao se apresentar em situações formais de ensino precisa ser reestruturada para atividades educativas, reconhecendo a necessidade de apropriação dos movimentos discursos inerentes à DC.

Em outras palavras, entende-se que o termo divulgação científica não pode ser compreendida como sinônimo de educar, mas se potencializa como prática educacional quando pensada em suas diferentes vertentes (RIBEIRO, 2007). Para Cardoso e colaboradores (2015) essa dimensão textual se reflete na necessidade de mobilizar não somente aspectos semânticos do discurso, mas a concepção da circulação das ideias provindas dos diferentes espaços sociais em que esses materiais são produzidos, sendo necessário, em distintos aspectos históricos e culturais, reconhecer elementos que contextualizem as dimensões do fazer científico.

Esses estudos, cujo enfoque está na produção de texto de divulgação científica e suas inserções no espaço escolar, indicam que a tentativa de buscar compreender como se constituem socialmente as ações de divulgar pode dar subsídios importantes para mobilizar debates para a compreensão do termo. Podese, nesse contexto, entender essa reflexão a partir da classificação em: impactos 
(Qual o papel da divulgação científica na formação de seu público?) (SUGIMOTO et al., 2017); espaços (Quais os lugares em que ocorre ou se oportuniza divulgar ciência?) (DESCHAMPS, 2019); e produtos (Que materiais são produzidos? Como são produzidos?). Todos esses debates, portanto, passam pela pergunta primordial "Por que se faz divulgação científica?" ou, em outras palavras, qual o objetivo de trazer ao público essas temáticas científicas, seja esse público especialista ou não? (LANGAN; CHENG; HUNKA, 2019).

Fato é que essas questões podem ser feitas de modo explícito ou implícito, mas a tentativa de buscar responder esse debate de modo claro ainda tem se mostrado um desafio. Um dos motivos pode estar relacionado à divulgação científica estar presente em diferentes lugares como na mídia, na escola, ser objeto de análise nas pesquisas em ensino de ciências ou estudo em disciplinas das universidades. Consequentemente, os compromissos acabam sendo diversos, assim, seus espaços, impactos e produtos.

Aolongo dos anos essas questões foram sendo mais bem articuladas, pensadas e tratadas na academia, passando de atividade, por vezes, intuitiva de alguns atores da DC (cientistas, jornalistas) para se constituir como tema de pesquisa. Exemplo dessas preocupações pode ser representado na edição do periódico International Journal of Science Education de 1991, que se dedicava ao tema "divulgar ciência". Os trabalhos se constituíam de estudos sobre a compreensão pública da ciência nos EUA (WILKIE, 1991), séries de livros científicos (DIXON, 1991), clubes de ciências nas escolas (KINGSLAND, 1991), atividades em museus, centros e aquários (PRICE \& HEIN, 1991; MADDOCK, 1991; KELSEY, 1991) dentre outros. O que esses trabalhos tinham como preocupação há cerca de 30 anos, de modo geral, era instigar os alunos a se engajarem na compreensão do conhecimento científico.

No entanto, esses pesquisadores, naquele momento, buscavam fazer conjecturas futuras sobre o papel daquelas atividades na vida dos visitantes e alunos que participavam das propostas ou tinham contato com aqueles materiais. Stevenson (1991) apresentou uma pesquisa interessante sobre o impacto à longo prazo com 79 adultos e crianças que participavam de uma visita ao . Os dados mostravam que após seis meses, $60 \%$ dos visitantes conseguiam descrever a visita, $14 \%$ lembravam-se dos sentimentos que a visita suscitou e $26 \%$ traziam algum pensamento ou memória sobre o tema. O que chama atenção nesse trabalho é que se considerava o fato dos sujeitos conseguirem lembrar-se de detalhes da visita como algo bom, ou seja, considerava-se a visita como um sucesso. Contudo, apenas $14 \%$ dos pesquisados se lembravam do sentimento que aquela interação evocou neles. Essa dimensão afetiva ou emocional tinha, à vista do artigo, tido um impacto menor diante de outras experiências que a visita tenha-lhes instigado. Sendo pouco explorada pelos autores, esse poderia ser um elemento importante para compreender de que modo as situações vivenciadas com a ciência podem ultrapassar lembranças de cunho racional para aspectos afetivos que permeiam ou poderiam permear o saber científico (DAVIS; BELLOCCHI, 2018).

Contudo, de modo geral, pode-se apontar que esses trabalhos refletem uma compreensão de que consumir divulgação científica não é algo trivial, sendo tratado como um momento específico na formação do aluno, mas que pode estar associado à trajetória de cada agente social e isso reflete de modo significativo 
nos modos como esses sujeitos compreendem e sentem essas atividades ao longo de toda sua vida. Jacobi e Schiele (1988) apontavam nos anos 80 sobre esse "consumo" não ser banal e a necessidade de antemão possuir certo "aparato cultural" para se aproximar da divulgação científica. Para eles o conhecimento anterior é peça central para compreender os fracassos e desafios encontrados pelos divulgadores em suas tentativas de aproximar a ciência do público. Assim, para esses autores, as produções da DC em si não dão conta de promover qualquer tipo de encorajamento para aprender ou gostar de ciências se não houver, antes, alguma aproximação com o conhecimento provindo do contexto social e familiar do público a que se pretende atingir, interagir e dialogar. Talvez para o trabalho de Stevenson (1991) seria interessante trazer maiores detalhes sobre os $14 \%$ dos visitantes que reagiram emocionalmente aos experimentos e atividades vivenciadas, possibilitando aprofundar tal dimensão emocional que marcou esses sujeitos.

Voltando ao Brasil dos últimos anos, observa-se que esses temas ainda são emergentes, existindo diferentes conhecimentos mobilizados para a construção de entendimentos sobre o que é divulgar a ciência. Artigos como os de Ferreira e Queiroz (2012) e Nascimento e Rezende (2010) trazem panoramas sobre o que é fazer pesquisa em divulgação científica na área de ensino de ciências, analisando em diferentes periódicos, teses e dissertações, os perfis e interesses dos pesquisadores sobre a temática. Do ponto de vista da estrutura e escolhas teóricas, chama a atenção para as dificuldades que parecem desafiar os profissionais quando esses procuram trazer conceituações ou diálogos teóricos. São trabalhos, em geral, que não tratam epistemologicamente dos problemas, em face ao desafio de construir interfaces com outras áreas do conhecimento. Conforme apontado anteriormente, reconhece-se aqui uma necessidade de abarcar diferentes demandas de diferentes intelectuais e áreas para a compreensão dessa atividade social.

De certo modo, o mesmo problema trazido por Jacobi e Schiele, em 1988, parece persistir nos dias atuais. Ou seja, como mobilizar diferentes áreas do saber para construir sentidos para a divulgação científica e, ao mesmo tempo, promover a reflexão sobre o aumento dos impactos que se pode provocar com seus produtos e saberes?

Um caminho possível para tentar dar suporte aos tais debates é reconhecer que a negociação de sentidos não pode ser compreendida unicamente como um aparato subjetivo, mas como um conjunto complexo de interpretações que envolvem, também, as construções sociais dos quais geram entendimentos e afeições por conhecimentos ditos racionais como a ciência (BOURDIEU; CHAMBODERON; PASSERON, 2015). Desse modo, em defesa de uma divulgação científica que possa ser um desencadeador do engajamento dos alunos aos estudos formais do conhecimento da ciência e, em especial, aos saberes da física, se pretende neste artigo discutir o viés híbrido da divulgação da ciência e, ao mesmo tempo, da representação de seu trabalho criativo que emerge de diferentes lugares sociais que a compõe. Desse modo busca-se compreender:

\section{Como o conceito de fronteira na perspectiva sociológica pode ser um importante instrumento teórico para congregar objetivos e ações no âmbito dos estudos em divulgação cientifica, possibilitando, assim, construir uma visão epistemológica que possa congregar às pesquisas em ensino de ciências relacionados a essa temática?}


Portanto, neste trabalho, o conceito de fronteira permitirá tratar a divulgação científica enquanto espaço de encontro entre dois mundos a partir de um estudo de caso. Entendendo para além dos produtos e dos muitos espaços sociais que dela fazem parte (como a comunicação científica), visa compreender o sentido dos discursos produzidos pelos cientistas e a existência de diferentes objetivos que nascem da aproximação de diferentes culturas (como a escolar e a da ciência). Pretende-se, assim, apresentar um sentido sociológico para tratar a divulgação científica de modo que possibilite reconhecer os atores e propósitos atribuídos às ações estudadas e problemas intrínsecos às pesquisas acadêmicas como apontadas por Nascimento e Rezende (2010).

Subsidiado por três modelos de fronteira: fronteira que separa, fronteira como frente e fronteira que une (ÁGUAS, 2013) espera-se dar suporte para uma análise das diferentes perspectivas que surgem do encontro de distintos campos sociais, tratando a fronteira como o lugar de encontros e desencontros. Para tal objetivo, será apresentada uma estrutura pautada:

- no estudo dos conceitos de campos de Pierre Bourdieu buscar-se-á dar um panorama geral sobre como se compreende o espaço social em que atuam seus agentes e como suas formas de compreender o mundo associam-se a determinada estrutura social;

- apresentar-se-á a caracterização dos debates sobre o conceito de fronteira em que serão discutidos os sentidos de fronteira na sociologia para clarificar as dimensões de interação debatidas nesse artigo;

- apresentar-se-á a análise das entrevistas dos cientistas divulgadores como um estudo de caso do debate teórico tratado e representado pelo campo científico;

- e nas considerações finais pretende-se discorrer sobre o potencial de tal abordagem para os estudos da divulgação científica em interface ao espaço escolar.

\section{A TEORIA DE CAMPOS E O CONCEITO DE FRONTEIRA}

A preocupação de Pierre Bourdieu com os espaços sociais ganhou destaque em artigo publicado em 1971 sob o título "Une interprétation de la théorie de la religion selon Max Weber". O autor pretendia, nesse trabalho, discutir o modo como o discurso é recepcionado e estaria, de certo modo, constituído de um espaço social em que a estrutura e relações de poder proporcionariam interpretações simbólicas caracterizadas pelo campo social do qual vivem e lutam os atores e seu público. $\mathrm{Na}$ teoria, cada um desses agentes representam um interesse específico no campo de poder: alguns dominantes e outros dominados.

Para tentar compreender tais interações e processos Bourdieu (2003) elabora a ideia de campo que se constitui como um espaço social que depende da distribuição, desigual, de capitais, algumas vezes instituídas por posses simbólicas entre os agentes nessa estrutura baseada em lutas pela dominação. Capitais econômicos e culturais são relevantes no campo, seguindo a lógica: 
Na primeira dimensão, os agentes se distribuem de acordo com o volume global do capital possuído, aí incluídos todos os tipos; na segunda, de acordo com a estrutura desse capital, isto é, de acordo com o peso relativo do capital econômico e do capital cultural no conjunto de seu patrimônio; na terceira, de acordo com a evolução, no tempo, do volume e da estrutura de seu capital. (BOURDIEU, 1996, p. 30).

O que essas considerações significavam é que a posse do capital em si não tem sentido se for motivado apenas pelo mero acúmulo. O capital deve ter um papel significativo de reconhecimento no campo para, então, poder conduzir seu portador a posições de poder e decisão no espaço de lutas em que atua. Assim, o campo expressaria um espaço global onde os agentes buscam o reconhecimento e as posições na estrutura do campo através das lutas e das disputas pelo poder. $\mathrm{O}$ objetivo de tais lutas é a manutenção ou a transformação da lógica estabelecida na estrutura do campo (BOURDIEU, 1996).

O campo científico, que foi interesse do trabalho de Bourdieu, pode ser compreendido como um microcosmo onde as lutas e posições estruturam a lógica das disputas entre cientistas. As lutas no campo científico se dão na busca pela autoridade científica e pela competência científica. Essa busca se daria pela dupla face do processo. Por um lado, o desejo por uma descoberta científica e a contribuição intelectual para a área de conhecimento em que atua e, por outro lado, pelo desejo comumente de prestígio, poder, fama e reconhecimento político no campo. No entanto, Bourdieu (1996) aponta que o processo para aquisição de qualquer um dos dois (capital científico puro e o capital científico político) é complexo e, portanto, conduzindo a uma vida profissional inteira para aquisição de um ou outro reconhecimento.

As artimanhas de ações políticas são, portanto, artifícios que balizam o sentido da pesquisa, sua relevância. Nesse sentido, seriam indissociáveis os conflitos epistemológicos e políticos, pois o último instaura, na teoria bourdieusiana, medidas burocráticas para consolidar as maneiras "corretas" de fazer ciência. Em outras palavras, não existe uma escolha científica, mas ações científico-políticas que se configuram como estratégias de publicações, métodos e apresentações de resultados, de modo a garantir o lucro científico, ou seja, a obtenção do reconhecimento. Cabe salientar que Bourdieu não ignorava a construção intelectual da ciência, assim como, a particularidade da epistemologia das ciências naturais em detrimento das ciências dos homens (BOURDIEU; CHAMBOREDON; PASSERON, 2015), contudo, acreditava na construção social como parte desse processo de produção do saber científico.

O que vem se consolidando, no âmbito da reflexão intelectual dos autores, é como a divulgação científica pode ser considerada uma ação constituída por interesses provindos do campo científico e de outros espaços sociais ${ }^{1}$ (por vezes podendo ser já estabelecidos como campo, outras vezes não). Grillo (2013) aponta que tais regras do campo científico acabam sendo um regulador importante da divulgação científica, trazendo e por vezes controlando, a partir de seus instrumentos de mediação, os saberes e práticas da ciência. Em particular, para pensar sobre essa perspectiva, a ideia de aproximação entre campos pode ser uma forma inicial de tratar essa temática em ascensão, possibilitando a constituição de um quadro 
teórico-metodológico para os estudos da divulgação científica. Para isso, utilizar o conceito de fronteira como o lugar que une diferentes campos e possibilita condições para pensar e agir, em especial, nas pesquisas em ensino de física e ciências, pode ser um potente instrumento reflexivo de aproximação entre espaços sociais. Assim como, constituir entendimento acerca da esfera social através de reconhecimento das especificidades e interesses sociais, culturais e econômicos que permeiam os campos que participam do processo de divulgar a ciência.

\section{A FRONTEIRA ENTRE CAMPOS}

O conceito de fronteira é indissociável dos estudos sobre cultura, visto que ambos nascem e dependem de sua existência mútua. O entendimento de fronteira existe para delimitar e reconhecer a distinção entre identidades de agentes sociais visando, por sua vez, compreender aspectos culturais que definem tais distinções (RIBEIRO, 2005). Esse espaço criativo, que se sobrepõe aos diferentes agentes sociais e instituído por diferentes modos de pensar, foi chamado por alguns autores na sociologia de fronteira (RIBEIRO, 2005; MARTINS, 1996).

Esse conceito, inicialmente tratado no âmbito da geografia e da antropologia, como marca territorial ou limite geográfico, ganhou outros sentidos ao longo do tempo, uma vez que a demarcação espacial não poderia representar a condição de transformação que emerge desse encontro com o outro (MARTINS, 1996). Algumas linhas da sociologia trata esse conceito como uma aproximação e não uma transposição para além das fronteiras. Ele se articula na junção e não no movimento de transpor (MARTINS, 2001). Martins (1996) busca debater a fronteira como o lugar da alteridade, onde a realidade surgida no conflito permite, na fronteira, reconhecer o outro, descobrir o outro e a si mesmo. Para o autor:

A fronteira só deixa de existir quando o conflito desaparece, quando os tempos se fundem, quando a alteridade original e mortal dá lugar à alteridade política, quando o outro se torna a parte antagônica de nós. Quando a História passa a ser a nossa História, a História da nossa diversidade e pluralidade, e nós já não somos nós mesmos porque somos antropofagicamente nós e o outro que devoramos e nos devorou (MARTINS, 1996, p. 27)

Para Martins (2001), o pensamento crítico pode surgir na fronteira onde é preciso reconhecer que as interações são exercidas na negociação, na mobilidade constante de reconfigurar essa fronteira a partir das pertinências do diálogo e das imposições feitas entre os agentes sociais. Nesse sentido, é preciso evitar a tendência de compreender a fronteira como linha que separa, evitando qualquer tipo de mediação. É, sim, preciso compreender esse lugar como espaço de encontro e partilha (RIBEIRO, 2005).

Não requer, contudo, que se ignore os limites desse entendimento, que se transfigure os problemas existentes das relações sociais reais, das imposições e lutas de poder que geram a violência e a exclusão. Para evitar tais concepções Ribeiro (2005) chama a atenção para a necessidade de compreender a fronteira como um lugar onde conflitos são parte constante no processo de reconhecimento da cultura do outro: 
Conceitos como os de identidade diaspórica, hibridação, mestiçagem, não dispensam, assim, uma especificação das tensões que lhes são inerentes de modo mais aprofundado do que muitas vezes é o caso nos usos mais marcadamente eufóricos desses conceitos (RIBEIRO, 2005, p. 484)

De modo a compreender essas diferentes possibilidades interpretativas Águas (2013) traça um panorama dos sentidos e possíveis modelos de fronteira que buscam, quando articulados, promover entendimentos sobre as aproximações entre distintas culturas e seus desafios. $\mathrm{Na}$ tentativa de clarificar essas ideias, Águas (2013) debate três modelos que a autora não reconhece como excludentes. A fronteira que separa que representa as abordagens que instituem delimitações dos espaços, simbólicos ou geográficos, demarcando as identidades a partir dos territórios. A fronteira como frente que representa as abordagens associadas ao front, ao avançar para ganhar territórios. Ao contrário do primeiro modelo que é fixo, este possui o movimento da fronteira como constante distanciar-se do centro. Sua fluidez, portanto, é marcada pela criatividade e "também por relações desiguais e pelo poder sem limites" (ÁGUAS, 2013, p. 3). Por último, a fronteira que une revela o lugar do encontro e da negociação. Ela não divide como a fronteira que separa e nem avança como a fronteira como frente.

Esta fronteira pode surgir e desaparecer, mudar de forma, e tem na fluidez uma das suas principais características. Nesse sentido, o aquém da fronteira é um espaço ocupado, bem como o além da fronteira. E é na fronteira que esses mundos se encontram (ÁGUAS, 2013, p. 3).

Reconhece-se na fronteira que une um deslocamento dos focos centrais, das determinações eimposições dos campos para encontrar na margem o espaço do diálogo. Não deixa aqui de ser uma crítica às posições teóricas centradas unicamente nas lutas desiguais de poder no campo, deslocando o foco do debate para as atividades marginais. De certa forma, reconhece-se uma visão em que a marginalidade das interações não pode ser vista como depreciativa, mas o espaço de produção e reconhecimento do mundo do outro. Em outras palavras, lugar na fronteira que une, portanto, movimenta os sujeitos de suas posições ordinárias no campo, de seu reconhecimento no seu espaço social, de sua vanguarda e lutas enraizadas, para transformar o diálogo em ações de desafio e criação, constituídos da dúvida e da negociação em prol da elaboração do novo e do entendimento do outro (ÁGUAS, 2013).

Retomando o debate acerca da fronteira e a divulgação científica, pretendese reconhecer esse instrumento reflexivo como uma tentativa de compreender os diferentes atores que pensam o ato de divulgar e reconhecer os embates de ideias e sentidos como próprio dessa aproximação entre diferentes representantes dos espaços sociais de onde atuam. Por tal motivo, a divulgação cientifica como produção constituída na fronteira social pode ajudar na superação de tentativas, por vezes infrutíferas, de conceituar ou colocar esse ato de aproximar a ciência do público como uma representativa única, seja de um grupo social ou de um objetivo educacional. Assim, é preciso compreender a fronteira como espaço de articulação, engajamento e negociação em constante movimento e que guarda em si a historicidade como o lugar da reflexão. Nesse aspecto, a luta pelo engajamento 
do público com a ciência não perde seu sentido primordial, mas constitui uma trajetória possível de desvencilhar as amarras culturais conflituosas, gerando, portanto, outros modos sociais de atuação e interação.

Com o objetivo de trazer luz a esse debate, propõe-se defender que tal interação já vem ocorrendo nos trabalhos de divulgação científica que visam reconhecer suas dimensões educacionais. Em especial, buscar-se-á apresentar como existem diferentes interações na divulgação científica e, ao mesmo tempo, defender que tal compreensão é capaz de aproximar e mobilizar diferentes interpretações e sentidos para constituir um diálogo efetivo entre o campo científico com seu entorno social.

\section{METODOLOGIA}

O presente trabalho se constitui como um estudo de caso dentro da metodologia qualitativa. Em partes, por se tratar de um olhar particular ao problema levantado no debate teórico e que, de certo modo, procura indícios do que se pretende perceber como hipótese de pesquisa. Ainda, é salutar indicar que a pergunta de pesquisa se constitui como tema embrionário, portanto, sendo necessário esclarecer sua limitação à tentativa de universalização do aparato metodológico para abarcar toda a divulgação científica. Ou seja, ele se constitui como estudo de caso pela sua dimensão particular e peculiar de mobilização dos cientistas ao fazer divulgação científica para o público escolar. Para May (2017) o estudo de caso é uma investigação empírica que visa entender um fenômeno da vida real, mas que ainda é obscura em sua compreensão, seja pelas fronteiras que permeiam o fenômeno estudado, seja pela complexidade dos atores sociais analisados. Ainda, esse tipo de pesquisa se torna importante por não buscar generalizar o problema em questão e é bem visto para variáveis difíceis de controlar (situações como a DC produzida por cientistas) (MAY, 2017).

Assim, o estudo de caso tratado nesse artigo refere-se aos cientistas divulgadores como representantes do campo científico (físicos de partículas) que mediam a aproximação de temas da ciência entre a universidade e o espaço escolar através de atividades educativas. Tal interesse se justifica, por apresentar, de maneira geral, um grupo de estudiosos da ciência que buscam na divulgação científica um lugar para dar voz às suas pesquisas através da aproximação com a sociedade (a escola no caso estudado). Assim, em termos dos estudos da fronteira, torna-se um grupo relativamente rico em termos metodológicos para coletar concepções, interesses e desafios no ato de divulgar que representam parte dos aspectos sociais que permeiam o campo científico e que se refletem ao produzir atividades de divulgação científica. Cabe salientar que ao olhar para um campo não é possível definir-se o sentido de fronteira que só surge na aproximação dentre espaços sociais distintos, mas os dados pretendem, nesse trabalho, conduzir a um tema emergente cujo resultados possam indicar as potencialidades do debate para futuras pesquisas.

$\mathrm{O}$ material coletado associa-se às entrevistas com cientistas brasileiros que fazem divulgação científica nas universidades de origem e no acelerador de partículas Larger Hadron Collider (LHC). A Organização Europeia de Pesquisa Nuclear (CERN) abriga um conglomerado de pesquisa onde atuam diferentes profissionais ligados à ciência como engenheiros, químicos, físicos, educadores 
e divulgadores da ciência. As entrevistas produzidas com esses cientistas tiveram como objetivo compreender os sentidos e negociações que eram produzidas, no âmbito das ações de divulgar do laboratório, por esses profissionais e seus interlocutores. Essas atividades se dividiam em ações como: palestras, recepção de alunos do ensino médio nas universidades, eventos de física de partículas destinados à escola básica, formação de professores do ensino médio etc.

A partir da construção de um protocolo de entrevista que buscasse compreender as diferentes fases e interfaces sociais da trajetória desses entrevistados, foram analisados os discursos dos pesquisados à luz da teoria social de fronteiras. Cabe salientar que as "respostas e os comentários dos respondentes não são encarados como relatos da realidade feitos a partir de um repositório fixo" (HOLSTEIN; GUBRIEN, 1997) e, portanto, reconhece-se que influenciam a esses resultados as diferentes trajetórias históricas. Nesse caso, a ideia de construir entendimentos sobre os discursos é uma tentativa de reconhecer dentro do debate sobre fronteira, como estão sendo tratados os impactos e objetivos de divulgar dentro desse arcabouço teórico. Os limites desses discursos referem-se aos modos como cada profissional vê sua própria trajetória e sua posição na hierarquia científica, contudo, procuramos no trabalho, reconstruir o discurso a partir dos itens que se sobressaíram ao interesse conceitual da ideia de fronteira.

As entrevistas foram produzidas em 2015 e 2016 com físicos de partículas que representam uma parcela dos profissionais que trabalham com atividades de divulgação científica no CERN e, mais especificamente, no Brasil. São profissionais que atuam nas universidades públicas paulistanas, mas que dialogam com diferentes instituições no Brasil e exterior, sejam nas colaborações de pesquisa, nos pósdoutorados ou nos eventos que participam. A entrevista não tinha o objetivo específico de compreender as concepções de fronteira que estavam sendo tratadas nas ações de divulgar desses entrevistados, mas nos diferentes sentidos atribuídos às práticas de divulgar desses profissionais.

Como não havia, antemão, um referencial de análise que pudesse dar suporte para a proposta de analisar indícios da ideia de fronteira, optou-se, neste trabalho, por utilizar algumas técnicas propostas por Bardin (1977) no método de Análise de Conteúdo. Assim, organizou-se a "leitura flutuante" para compreender os possíveis campos de aproximação que estavam sendo apresentados nas transcrições das entrevistas. Em seguida, foram trabalhadas as "unidades de registro" para exemplificação das "categorias" em que se estavam procurando interfaces entre o campo científico e a escola. Contudo, é salutar lembrar que tais categorias não se constituíram no processo de análise, mas pode-se dizer que foram elaboradas anteriormente no diálogo com os referenciais teóricos trazidos nesse trabalho. O que aqui se afasta da proposta de Bardin (2009).

Pretende-se nas próximas seções discutir a intencionalidade das práticas e propostas, para melhor compreender que a fronteira pode se constituir como espaço social de produção da divulgação científica, assim como, apresentar os muitos interesses que a compõem. Em outras palavras, busca-se introduzir debates associados às questões como o tipo de fronteiras que estamos falando, reconhecendo ou tratando e qual a natureza dessas fronteiras quando cientistas falam sobre a relevância de fazer divulgação científica para alunos do ensino médio 
ou das escolas em geral? É salutar compreender que se constitui nessa pesquisa uma parte importante, contudo, não global do problema tratado, buscando, assim, indícios que possam dar suporte ao tema discutido.

Nesse sentido, os quadros apresentados nos resultados não são indicativos das fronteiras entre campos, mas de como os cientistas, agentes sociais que representam o campo cientifico, estão dando indícios de que a aproximação com a escola (espaço escolar) pode estar mobilizando elementos das fronteiras apontadas por Águas (2013). De mesmo modo, outros espaços sociais que não especificamente o escolar, como o campo político ou outros espaços representados pelos agentes que participam dessas ações estão sendo percebidos pelos cientistas. Assim como reconhecer as percepções do campo científico pelos entrevistados e como se aferem elementos que podem ser defendidos como indícios da constituição das fronteiras.

\section{RESULTADOS}

A interface da divulgação científica com outros espaços sociais como a escola acaba promovendo a elaboração de novos sentidos que são, na perspectiva teórica desse trabalho, construídos a partir da negociação de diferentes objetivos atribuídos pelos distintos campos ou espaços sociais representados pelos seus agentes. Essa negociação, defende-se, só pode ser produzida na fronteira entre campos, quando os atores sociais deixam de lado seus interesses específicos para dialogar e promover práticas educacionais em que diversas perspectivas sejam levadas em conta.

No entanto, ainda é preciso pensar de que maneira aqueles que produzem a divulgação científica e seus artefatos culturais percebem o sentido de divulgar. Questiona-se assim se esses sujeitos estariam dispostos a apresentar suas visões de mundo e produzir novas visões sobre a ciência a partir da colaboração com os representantes de outros espaços sociais. Para esse trabalho representam esse olhar e ideias cientistas brasileiros que atuam em instituições de pesquisa e que buscam promover, de modo prático, atividades de divulgação científica. Assim, ao propor ouvir os discursos dos cientistas sobre sua relação com a divulgação científica e seu público, pretende-se entender em que medida esses profissionais estão (ou não) entendendo que suas práticas não são ações meramente de apresentar a ciência ao público, mas possui vínculos com outras práticas como atividades pedagógicas e na formação cidadã na escola.

Para compreender a existência da fronteira ou a gestação da fronteira, era importante nessa pesquisa que se pudesse pensar como o campo científico, em proximidade com o espaço social da escola, poderia, potencialmente, produzir reflexões e impactos que pudesse fazer emergir uma outra prática para a divulgação científica. Prática essa que não fosse unicamente a ação provinda dos cientistas na universidade. Para promover tal reflexão associada ao campo científico alguns questionamentos foram colocados para o entendimento sobre o ato de divulgar, que envolvem:

1. O interesse dos cientistas pela atividade de divulgar a ciência;

2. As políticas públicas para fomentar a divulgação científica nas universidades; 
3. Formação para divulgar ciência que seja norteada por debates sociais e culturais para os cientistas;

4. Reconhecimento do campo científico para a prática de divulgar.

Diante do desafio imposto, foram estabelecidos três quadros de análise para compreender o que cientistas indicam em seus discursos sobre o papel da divulgação científica a partir de três esferas sociais: o seu próprio campo científico, no espaço escolar e na sociedade de modo geral, que aqui unicamente estabelecemos como espaço social. A escolha desses três lugares sociais não se dá ao acaso, mas pelas suas capacidades de permitirem vislumbrar em que medida cada um possui papel importante para pensar as possibilidades de diálogo, de cooperação e de entendimento dos impactos positivos e negativos que os cientistas percebem ao fazerem divulgação científica e que são, fundamentalmente, capazes de trazer um panorama sobre os aspectos de solidarização ou recusa dos interesses dos outros agentes que participam das interações na fronteira.

Para os quatro cientistas brasileiros analisados, optou-se por trazer considerações sobre os aspectos que influenciam suas práticas no ato de divulgar. Para todos os cientistas o perfil não parece mudar em termos de suas posições no campo científico, ou seja, todos possuem cargo de docente universitário e atuam há mais de 20 anos na área de física. Produzem atividades de divulgação científica em períodos relativamente longos na carreira e são representantes de grupos de pesquisas reconhecidos no país e fora dele.

O primeiro lugar a ser analisado é o espaço escolar, por se tratar de uma preocupação inerente a essa pesquisa e aparece em diferentes momentos nos discursos dos entrevistados. De modo geral, foram constatadas nas entrevistas, em determinados momentos, que há uma expectativa de afastamento da atividade de DC da atividade escolar, ao mesmo tempo que se considera a necessidade de aproximação do conhecimento científico com o espaço educacional da escola. O saber (ou conteúdo) é um desses fatores que perpassa essa ambiguidade entre o reconhecimento da relevância e responsabilidade que o cientista detém para o apresentar ao público. Outro fator importante desse debate se refere a uma tentativa de aproximação aos problemas escolares, reconhecendo que a divulgação científica e os cientistas possuem responsabilidades educacionais e encontram nos professores os sujeitos capazes de promover a aproximação e cooperação para pensar a divulgação científica como prática pedagógica (fronteira que une).

Em outros momentos, a ideia de levar a física de partículas para a escola apresenta uma perspectiva de reconhecimento da legitimidade da ciência (fronteira como frente). Isso ocorre, em especial, no que tange às práticas que envolvem atos em que a universidade recepciona os estudantes. Assim como percebe-se que os objetivos nesses momentos se modificam para construir uma divisão do trabalho em que o professor por vezes torna-se meramente o receptor. Pouco, no entanto, se refere ao distanciamento ou a exaltação da ciência (fronteira que separa) nesse tipo de ação. Por exemplo, pode-se perceber que os pesquisados compreendem que o papel da escola é produzir suas atividades enquanto os cientistas as suas, e pouco se observa sobre o entendimento de que a divulgação científica pode ser uma ação produzida coletivamente, por esses diferentes atores sociais. 
Como tentativa de especificar o amplo debate acima, no Quadro 1, ao incorporar as fronteiras em suas diferentes vertentes, pretende-se encontrar nos discursos dos cientistas elementos que emergem dessa perspectiva sociológica quando os mesmos apontam sobre a relação DC e escola. Em determinados momentos, se reconhece que tais trechos podem ser incorporados em diferentes instâncias fronteiriças, visto sua complexidade e mutação constante, contudo, eles se encaixam em um degradê conceitual que visa indicar leituras sobre o problema levantado e não, exclusivamente, colocar os discursos em uma ordenação linear. Nesse sentido, podemos observar exemplos como ocorre com o cientista 1 quando o mesmo entende que o conteúdo escolar deve ser ensinado na escola, parecendo indicar afastamento das suas responsabilidades em relação ao diálogo com os espaços formais de educação (coluna fronteira que separa), contudo, entende que a física de partículas precisa ser ensinada e que a participação dos cientistas em atividades de DC se torna fundamental para que isso ocorra (fronteira como frente). Se tal discurso parece ser uma contradição entre não se reconhecer como responsável ao mesmo tempo que se reconhece como sujeito necessário para inserir e promover o engajamento e inserção dos conteúdos na escola, o que se compreende nas representações dos quadros, em particular, no Quadro 1, é que a dimensão da fronteira leva a esse constante embate desses pesquisados sobre os sentidos de atuar em tais ações como a estudada. Insere-se, nesse contexto, o desafio de compreender em que medida os discursos apresentados na coluna "fronteira que une" não é uma tentativa de superar tal contradição encontrada nas duas primeiras colunas. Ainda que em alguns momentos pode-se reconhecer que alguns elementos são parte também das outras fronteiras, observa-se que reconhecer a necessidade do diálogo com a universidade perpassa, para esses profissionais, um reconhecimento de que a universidade precisa adentrar o mundo escolar, ouvir e se deixar mudar. Aprender, nesse sentido, reflete o que se entende na "fronteira que une" como o lugar em que ambos, escola e universidade, se colocam como capazes de promover novas possibilidades de parcerias na DC.

\section{Quadro 1. Espaço Escolar}

\begin{tabular}{|c|c|c|c|}
\hline $\begin{array}{l}\text { Espaço } \\
\text { Escolar }\end{array}$ & Fronteira que Separa & Fronteira como Frente & Fronteira que Une \\
\hline Cientista 1 & $\begin{array}{l}\text { - conteúdo escolar é } \\
\text { responsabilidade da } \\
\text { escola }\end{array}$ & $\begin{array}{l}\text { - introduzir o saber da } \\
\text { física de partículas na } \\
\text { escola } \\
\text { - a física entra na } \\
\text { escola para promover o } \\
\text { engajamento } \\
\text { - o saber científico entra } \\
\text { na escola para superar a } \\
\text { visão de ciência estática }\end{array}$ & $\begin{array}{l}\text { - promover o diálogo entre } \\
\text { universidade e escola } \\
\text { - apresentar o espaço da } \\
\text { universidade aos estudantes } \\
\text { da escola média } \\
\text { - complementar os saberes } \\
\text { dos professores através das } \\
\text { atividades } \\
\text { - aprimorar o uso da } \\
\text { linguagem no tratamento } \\
\text { com o público } \\
\text { - possibilitar a humanização } \\
\text { da física através da } \\
\text { interação cientista-aluno }\end{array}$ \\
\hline
\end{tabular}




\begin{tabular}{|c|c|c|c|}
\hline $\begin{array}{l}\text { Espaço } \\
\text { Escolar }\end{array}$ & Fronteira que Separa & Fronteira como Frente & Fronteira que Une \\
\hline Cientista 2 & $\begin{array}{l}\text { - prática científica se } \\
\text { aprende no laboratório } \\
\text { científico }\end{array}$ & $\begin{array}{l}\text { - superar a defasagem } \\
\text { do conhecimento no } \\
\text { âmbito da aprendizagem } \\
\text { da escola }\end{array}$ & $\begin{array}{l}\text { - promove o engajamento } \\
\text { escolar dos alunos em } \\
\text { relação aos estudos da física } \\
\text { - prepara os professores } \\
\text { para darem aulas mais } \\
\text { interessantes } \\
\text { - promove uma segurança } \\
\text { aos alunos em relação ao } \\
\text { que aprenderam no evento }\end{array}$ \\
\hline Cientista 3 & & $\begin{array}{l}\text { - possibilitar que o } \\
\text { evento entre na escola e } \\
\text { chegue para mais alunos }\end{array}$ & $\begin{array}{l}\text { - descaracterizar o processo } \\
\text { de construção do saber } \\
\text { científico do olhar escolar } \\
\text { - ajudar o professor a } \\
\text { construir aulas sobre física } \\
\text { de partículas } \\
\text { - dar autonomia para o } \\
\text { professor construir suas } \\
\text { próprias ações associados } \\
\text { ao evento } \\
\text { - compreender as demandas } \\
\text { da escola pela formação de } \\
\text { professor } \\
\text { - fazer parcerias com as } \\
\text { secretarias de educação }\end{array}$ \\
\hline Cientista 4 & & $\begin{array}{l}\text { - permite o uso da } \\
\text { linguagem científica } \\
\text { específica } \\
\text { - os professores } \\
\text { preparam os alunos } \\
\text { para o evento sem suas } \\
\text { escolas }\end{array}$ & $\begin{array}{l}\text { - cooperação entre } \\
\text { professores e cientistas } \\
\text { para levar evento para } \\
\text { escolas } \\
\text { - construir a melhoria do } \\
\text { evento com os professores } \\
\text { e alunos } \\
\text { - estimular as emoções } \\
\text { e engajamento nos } \\
\text { participantes } \\
\text { - buscar o diálogo com o } \\
\text { currículo escolar } \\
\text { - facilitar as ações do } \\
\text { professor em sala de aula } \\
\text { através da disponibilidade } \\
\text { para trabalhar e construir } \\
\text { novas atividades }\end{array}$ \\
\hline
\end{tabular}

Quando se observa como esses profissionais entendem o papel de seu ato de divulgar para o mundo em seu entorno (outros espaços sociais), percebe-se que há certa necessidade de buscar, no caso mais amplo, a legitimidade da ciência. Nesse contexto, o conhecimento específico indica algo que possa ser reconhecido como um elemento das diferenciações. Não é novidade que os agentes sociais da ciência têm, há cada dia mais, se distanciado do diálogo com o mundo exterior, 
contudo, ainda cabe melhor compreender em que medida esse afastamento pode ser considerado uma necessidade em termos da sobrevivência e/ou legitimação da ciência na sociedade. Mesmo que seja deveras preliminar fazer uma interpretação mais profunda sobre tal percepção, entende-se que aparece, em geral, pouco sobre a relação de parceria entre a ciência e a sociedade quando os cientistas pensam sobre o papel da divulgação científica e seus impactos nela (fronteira que separa). Ainda, há uma preocupação com o reconhecimento ou da imagem da ciência para a sociedade que soe como algo positivo. Essa tentativa é de construir uma visão dos cientistas como agentes sociais relevantes (fronteira como frente). A questão da participação do cidadão em problemas importantes sobre ciências ou uma visão mais filosófica sobre o papel desse conhecimento para o homem são parte de uma reflexão em que leva em conta o outro e aparece em determinados momentos dos discursos. Tais perspectivas empáticas sobre o sentido do divulgar possibilitam reconhecer que espaços de interação e produção de sentidos ainda permanecem nos discursos mesmo quando estes não tenham como objetivo comum a educação formal ou a formação específica das ciências (fronteira que une).

De modo mais objetivo, no Quadro 2, a exemplo do que é apontado acima pode-se perceber na análise dos cientistas 1 e 3 como a preocupação em fazer DC também perpassa outros espaços sociais mesmo quando se tem como objetivo divulgar na escola. Assim, elementos da procura por práticas que visem construir uma visão dos cientistas para a sociedade e o debate sobre financiamento público, de certo modo, entende-se, como uma tentativa de busca pela legitimidade da ciência em outras esferas sociais. Aqui, percebe-se que para esses cientistas, a DC é um lugar privilegiado de mostrar para o mundo, fora do campo científico, quem eles são e suas especificidades. Novamente, ao pensar em que medida os discursos $\mathrm{da}$ "fronteira como frente" poderiam ser representados na coluna "fronteira que separa", pode-se perceber que enquanto no primeiro existe uma preocupação com a dimensão de se legitimar diante do mundo fora do campo científico, na fronteira como frente, os cientistas procuram colocar suas práticas como necessárias para serem reconhecidas em outros espaços e campos sociais. A profissão é um fator determinante nesses discursos, quando esses cientistas dão indícios da necessidade da DC ser meio de incorporar e convencer novos adeptos para as pesquisas científicas. Novamente, como elemento mais significativo da "fronteira que une" é o diálogo. Chama aatenção quando os cientistas indicam o ouvir e incorporar aprendizagens com o objetivo de transformar o mundo, de aproximar a ciência da vida cotidiana das pessoas e intervir nas políticas públicas associadas à educação, ou seja, na possibilidade de inserir no campo político questionamentos e críticas aprendidos da interação com o espaço escolar. 
Quadro 2. Outros espaços sociais

\begin{tabular}{|c|c|c|c|}
\hline $\begin{array}{l}\text { Outros } \\
\text { espaços } \\
\text { sociais }\end{array}$ & Fronteira que Separa & Fronteira como Frente & Fronteira que Une \\
\hline Cientista 1 & $\begin{array}{l}\text { - existência de } \\
\text { cientistas brasileiros } \\
\text { - entrar no imaginário } \\
\text { social } \\
\text { - reconhecimento } \\
\text { da ciência enquanto } \\
\text { construção da saber }\end{array}$ & $\begin{array}{l}\text { - construção do } \\
\text { imaginário social da } \\
\text { profissão científica no } \\
\text { Brasil }\end{array}$ & \\
\hline Cientista 2 & & $\begin{array}{l}\text { - possibilitar diminuir } \\
\text { a procura por cursos } \\
\text { das humanas em } \\
\text { detrimento das exatas } \\
\text { - ajudar a transmitir } \\
\text { as pesquisas para a } \\
\text { sociedade } \\
\text { - ajudar o cidadão } \\
\text { brasileiro a estudar no } \\
\text { ensino superior }\end{array}$ & $\begin{array}{l}\text { - compreender que a física } \\
\text { precisa ser entendida } \\
\text { como algo para a vida } \\
\text { - ajudar a promover uma } \\
\text { reflexão sobre a relação } \\
\text { homem, natureza e } \\
\text { sociedade } \\
\text { - ajudar os estudantes } \\
\text { que não serão cientistas } \\
\text { a serem profissionais que } \\
\text { compreendam a ciência }\end{array}$ \\
\hline Cientista 3 & $\begin{array}{l}\text { - apresentar para } \\
\text { a sociedade o que } \\
\text { esta sendo feito com } \\
\text { os financiamentos } \\
\text { públicos para } \\
\text { pesquisa }\end{array}$ & & $\begin{array}{l}\text { - reconhecer e procurar } \\
\text { intervir nas políticas } \\
\text { públicas sobre educação }\end{array}$ \\
\hline Cientista 4 & & $\begin{array}{l}\text { - distribuir o } \\
\text { conhecimento para } \\
\text { aqueles que investiram } \\
\text { na ciência } \\
\text { - expandir o evento } \\
\text { - levar os conceitos } \\
\text { como retorno social } \\
\text { - compromisso do } \\
\text { pesquisador em tornar } \\
\text { acessível a informação }\end{array}$ & $\begin{array}{l}\text { - redescobrir as } \\
\text { carências e satisfazer } \\
\text { as necessidades da } \\
\text { população } \\
\text { - aproximar o } \\
\text { conhecimento das pessoas } \\
\text { - possibilitar o acesso do } \\
\text { saber }\end{array}$ \\
\hline
\end{tabular}

As discussões sobre os impactos da divulgação científica na formação dos cientistas já foram tratadas em artigos anteriores (WATANABE; KAWAMURA, 2015; WATANABE; KAWAMURA, 2016), contudo, longe de esgotar debate tão complexo, percebe-se que ao pensar os motivos pelos quais a divulgação científica pode produzir em termos de potencial ao campo científico, o discurso concentrase no que chamaremos de uma representação do microcosmo do laboratório. Por vezes, as compreensões dos pesquisados acerca dos impactos ou melhorias que 
poderiam ser percebidas dentro do campo científico caminham em diferentes sentidos, ora dando ênfase ao saber da ciência enquanto complexo e inacessível (fronteira que separa), ora reconhecendo as diferentes perspectivas educacionais que o compõem (fronteira que une). Em termos práticos possui o papel de cooptar ou instigar novos cientistas para os espaços de produção da ciência. Contudo, dentre todos, esse parece ser o menos privilegiado em termos de reconhecimento dos ganhos possíveis das práticas de divulgação científica quanto esta se dá na fronteira que une, ou seja, nas interações e negociações de sentidos. Assim há de certa forma uma dificuldade de abrir mão dos interesses da ciência ou migrar tais interesses para outras esferas que não sejam aquelas destinadas ao campo científico em si.

Por fim, se o Quadro 3 busca compreender como a DC, segundo os físicos de partículas, é incorporada no campo científico, fica evidente que as colunas da "fronteira que separa" e a "fronteira como frente" possuem papel importante nesse debate. Isto, pois ainda que os pesquisados pensem na DC como importante para ser incorporada na relação de aprendizagens mútuas com a escola (Quadro 1), ao passo que vão tratando seu lugar de trabalho, percebe-se que ainda não enxergam de modo claro os impactos disso para o campo científico. Para os cientistas 2 e 4, por exemplo, a atividade de DC serve como o lugar para mostrar o cientista em seu trabalho ou despertar nos alunos a vocação pela carreira científica. Ainda, se em alguns casos aparecem o cotidiano do cientista (fronteira que separa) e o dia a dia do cientista (fronteira como frente) em colunas distintas, elas se apresentam, nesse degradê de sentidos, pelas suas peculiaridades nos discursos. Enquanto no primeiro caso o cotidiano serve como uma imagem a ser construída para o imaginário social, no segundo caso ela se apresenta como um lugar de possibilidade mais próxima do convencimento de sua espetacularidade para possíveis cientistas (ampliar o campo científico).

Quadro 3. Campo científico

\begin{tabular}{|c|c|c|c|}
\hline $\begin{array}{c}\text { Campo ao } \\
\text { entorno da } \\
\text { produção } \\
\text { das } \\
\text { ações de } \\
\text { divulgar }\end{array}$ & $\begin{array}{c}\text { Fronteira } \\
\text { que Separa }\end{array}$ & $\begin{array}{l}\text { Fronteira } \\
\text { como Frente }\end{array}$ & $\begin{array}{l}\text { Fronteira } \\
\text { que Une }\end{array}$ \\
\hline Cientista 1 & $\begin{array}{l}\text { - público ignora o } \\
\text { saber científico } \\
\text { - conhecimento } \\
\text { intermediário } \\
\text { complexo }\end{array}$ & $\begin{array}{l}\text { - apresentar um } \\
\text { espaço de possíveis da } \\
\text { profissão de cientista } \\
\text { no Brasil } \\
\text { - apresentar a emoção } \\
\text { da atividade científica } \\
\text { - despertar vocações } \\
\text { - manter os quadros de } \\
\text { profissionais do campo } \\
\text { científico } \\
\text { - suporte para } \\
\text { financiamento de } \\
\text { pesquisa }\end{array}$ & $\begin{array}{l}\text { - mostrar ao aluno o } \\
\text { desenvolvimento da física } \\
\text { - apresentar o saber } \\
\text { científico sendo tratado no } \\
\text { âmbito dos experimentos } \\
\text { em laboratórios } \\
\text { - preocupar-se em } \\
\text { apresentar uma visão do } \\
\text { cientista mais próxima da } \\
\text { sociedade } \\
\text { - apresentar aspectos } \\
\text { emocionais nas interações } \\
\text { com os alunos de modo a } \\
\text { descaracterizar a visão do } \\
\text { cientista solitário }\end{array}$ \\
\hline
\end{tabular}




\begin{tabular}{|c|c|c|c|}
\hline $\begin{array}{c}\text { Campo ao } \\
\text { entorno da } \\
\text { produção } \\
\text { das } \\
\text { ações de } \\
\text { divulgar }\end{array}$ & $\begin{array}{l}\text { Fronteira } \\
\text { que Separa }\end{array}$ & $\begin{array}{l}\text { Fronteira } \\
\text { como Frente }\end{array}$ & $\begin{array}{l}\text { Fronteira } \\
\text { que Une }\end{array}$ \\
\hline Cientista 2 & $\begin{array}{l}\text { - adquirir a noção de } \\
\text { fazer ciência }\end{array}$ & $\begin{array}{l}\text { - ajuda a analisar } \\
\text { dados dos detectores } \\
\text { modernos } \\
\text { - mostrar o que os } \\
\text { cientistas fazem } \\
\text { - cooptar novos } \\
\text { cientistas para os } \\
\text { grupos de pesquisa } \\
\text { - apresentar o diaadia } \\
\text { do cientista } \\
\text { - ser cientista } \\
\text { possibilita aumento do } \\
\text { capital social e cultural }\end{array}$ & \\
\hline Cientista 3 & $\begin{array}{l}\text { - evento nasce de } \\
\text { demanda institucional } \\
\text { - apresentar o saber } \\
\text { aos estudantes }\end{array}$ & $\begin{array}{l}\text { - cooptação de mão } \\
\text { de obra para os } \\
\text { laboratórios } \\
\text { - levar as questões } \\
\text { científicas para a sala } \\
\text { de aula } \\
\text { - apresentar a ciência } \\
\text { dos aceleradores }\end{array}$ & $\begin{array}{l}\text { - apresentar aspectos } \\
\text { do fazer científico } \\
\text { como concentração, } \\
\text { interpretação e debate }\end{array}$ \\
\hline Cientista 4 & $\begin{array}{l}\text { - apresentar o } \\
\text { cotidiano do cientista } \\
\text { - apresentar o CERN }\end{array}$ & $\begin{array}{l}\text { - despertar vocações } \\
\text { - desmistificar a visão } \\
\text { do cientista }\end{array}$ & \\
\hline
\end{tabular}

Ao buscar investigar como compreendem e mobilizam discursos para tratar a divulgação científica pelos cientistas no contexto escolar e social mais amplo, se propôs reconhecer se havia indícios de que a divulgação científica elaborada ou pensada na fronteira poderia ser reconhecida ou potencialmente percebida nessas três esferas sociais. Ainda que os instrumentos ou representações não sejam globalmente representativas, pode-se defender que são importantes interlocutores do debate proposto. Tal limitação da pesquisa aparece na falta de outros discursos como dos atores sociais da escola e "consumidores" da divulgação científica produzida por cientistas. Além da própria emergência em entender elementos políticos que perpassam a profissão científica e a universidade, catalisando práticas e discursos marcados por determinados momentos históricos. Contudo, pode-se reconhecer que os resultados obtidos levam à compreensão de que a dimensão educacional e a necessidade de escuta e negociação do mundo do outro são práticas que 
potencialmente se manifestam em diferentes momentos. Atos que são fundamentais para pensar em uma divulgação científica enquanto construção coletiva em que participam cientistas, educadores, alunos e a sociedade de modo geral.

\section{A DIVULGAC̣ÃO CIENTÍFICA COMO FRONTEIRA}

Ao passo que se pretende demonstrar que a ideia de pensar a divulgação científica como uma prática multifacetada, em que atuam diferentes atores e consequentemente, distintos objetivos, pretende-se indicar que a ideia de fronteira pode ser um importante instrumento para reflexão, que possibilite compreender as suas especificidades como área de pesquisa e prática cultural. Seja no ensino de física (e ciências), quando são mobilizadas diferentes ações e reflexões sobre os modos como a DC se constitui nas práticas pedagógicas, seja no discurso dos cientistas (representantes do campo científico) que compreendem a DC como o lugar de interação e superação das expectativas do saber científico como conhecimento estático ou sem utilidade para a vivência cultural e social.

Cabe, contudo, reconhecer que nem sempre o sentido de fronteira como aponta Águas (2013) é estritamente positivo, mas pode, por vezes, demonstrar e congregar procedimentos que levem ao afastamento ou dominação daqueles que participam do processo. Para pensar essas situações é necessário questionar em que medida deve-se defender:

- A divulgação científica como atividade produzida na fronteira que separa;

- A divulgação científica como atividade produzida na fronteira como frente;

- A divulgação científica como atividade produzida na fronteira que une.

Os objetivos, portanto, que permeiam a divulgação científica são, na verdade, um misto de diferentes sentidos que se atribuem a ela. Nesse caso, pode-se compreender que quando pensa-se em uma divulgação científica que é produzida em uma fronteira que separa pode-se reconhecer que:

- Escola tem seu saber educacional e o laboratório seu saber especifico com pouca ou sem articulação;

- Saber da ciência é complexo e só alguns podem ter acesso efetivo a ele;

- O trabalho do cientista deve ser apresentado no espaço de atuação do cientista;

Nessa perspectiva a divulgação científica ganha uma dimensão de separação ou afastamento do outro. Procura a imposição e a legitimidade a qualquer preço, provocando, assim, difundir aquilo que é inacessível e atuando como prática de impor o poder e a dimensão espetacular da ciência. Nesse sentido, a fronteira em que os diferentes campos e espaços sociais atuam para afastar-se um ao outro, ou seja, se transforma em produções que visam instituir uma separação entre eles. Contudo, quando ainda persiste a ideia de que é possível expandir o poder da ciência para outras instâncias ou dela se nutrir para aumentar o poder do campo científico, essa fronteira como frente aparece em objetivos como: 
- Fazer divulgação científica para obter mais estudantes nos cursos de graduação;

- Requerer da sociedade mais reconhecimento sobre a relevância da ciência;

- Defender a legitimidade e poder dos físicos no Brasil.

Tais perspectivas atuam como possibilidades de pensar a divulgação científica como o lugar midiático da ciência e seus espaços de produção. Objetivase construir aproximações cujo fruto a ser colhido é o aumento do poder da ciência, contudo, com o intuito de cooptar a sociedade ao entorno do campo científico para legitimar suas práticas. Essa divulgação científica em que a fronteira serve como um campo de batalha intelectual e reconhecimento social não pretende, em demasia, que outros agentes se apropriem desse conhecimento sem, contudo, que haja um lucro simbólico ao campo científico.

A fronteira que une, talvez, seja aquela que melhor representa os objetivos da área de ensino de ciências, em que se construa uma divulgação científica onde a fronteira seja o lugar que aproxime os diferentes e que estes se apropriem dos diversos saberes que a permeiam para elaborar práticas e ações coletivas. Essas dimensões aparecem quando:

- Se reconhece a responsabilidade educacional dos cientistas para com a escola;

- A ciência é um instrumento intelectual primordial para o homem reconhecer e se reconhecer no mundo;

- A questão da cidadania se torna parte estruturante do ato de produzir e divulgar ciência.

Por tal motivo, a ideia de fronteira pode ser um instrumento importante para pensar aspectos sociais, culturais e conceituais que são parte das práticas da divulgação científica. Ao buscar o desvelamento dos diferentes objetivos, se pretende construir estratégias de negociação em que se privilegie, ao menos, no âmbito das ações de divulgar no contexto do ensino de ciências, aspectos de aproximação como as debatidas no contexto da fronteira que une (ÁGUAS, 2013).

A partir de tal discurso foi elaborado no Quadro 4 uma tentativa de apresentar os perfis de debates e modos de negociação que levem os atores a reconhecerem e trabalharem para a produção de atividades de divulgação científica que visem a construção de ações onde levem aos momentos de interação em que essas práticas se configurem na fronteira que une. 
Quadro 4. Análises e práticas

\begin{tabular}{|c|c|c|}
\hline & Fronteira que Separa & Fronteira como Frente \\
\hline $\begin{array}{l}\text { Reconhecendo } \\
\text { perfis }\end{array}$ & $\begin{array}{l}\text { DC produzida por agentes de } \\
\text { um único campo ou espaço } \\
\text { social; } \\
\text { Saber sobre o conhecimento } \\
\text { científico é o objetivo fim da } \\
\text { ação de divulgar; } \\
\text { Discurso da divulgação } \\
\text { científica reflete um único ponto } \\
\text { de vista; } \\
\text { Sem compromisso com as } \\
\text { especificidades do público } \\
\text { (escolar ou não) }\end{array}$ & $\begin{array}{l}\text { DC pode ser produzida por } \\
\text { diferentes atores sociais, mas } \\
\text { somente a ciência prevalece; } \\
\text { Aspectos salvacionistas da } \\
\text { ciência sem debates sobre suas } \\
\text { limitações; } \\
\text { Pontos de vistas em que } \\
\text { convergem para um único tipo } \\
\text { de pensamento, em geral, da } \\
\text { ciência como lugar privilegiado } \\
\text { para responder os problemas } \\
\text { levantados; }\end{array}$ \\
\hline $\begin{array}{l}\text { Modos de } \\
\text { negociação } \\
\text { para chegar à } \\
\text { Fronteira que } \\
\text { Une. }\end{array}$ & $\begin{array}{l}\text { Propor avaliações das ações de } \\
\text { divulgação científica por outros } \\
\text { profissionais como jornalistas, } \\
\text { professores e alunos da escola } \\
\text { básica etc.; } \\
\text { Levar em conta aspectos } \\
\text { educacionais como linguagem, } \\
\text { currículo escolar, interesses } \\
\text { dos alunos e professores aos } \\
\text { temas tratados etc.; } \\
\text { Trazer as controvérsias } \\
\text { associadas aos temas } \\
\text { científicos e indicar outros } \\
\text { pontos de vista sobre o } \\
\text { conhecimento tratado; } \\
\text { Grupos com diversidade } \\
\text { profissional para compor } \\
\text { e propor as atividades de } \\
\text { divulgação científica; } \\
\text { Espaços de debates sobre } \\
\text { aspectos filosóficos, } \\
\text { sociológicos e culturais que } \\
\text { precisam ser levados em conta } \\
\text { para a elaboração de materiais } \\
\text { de divulgação científica que } \\
\text { não se constituam como } \\
\text { unicamente associados ao } \\
\text { saber da ciência, mas que } \\
\text { tenham na ciência o diálogo } \\
\text { com aspectos educacionais. }\end{array}$ & \\
\hline
\end{tabular}

Ainda que esse debate precise ser mais bem explorado, delimitado e que careça de maior entendimento das ações efetivas na arena social que pode se 
constituir na fronteira, é importante salientar que dimensões de negociação são sempre necessárias para indicar caminhos de diálogo e instruir novos pensadores nas práticas de divulgação científica. Os indicativos apresentados no Quadro 4, portanto, visam provocar o leitor a pensar sobre impactos e limitações que as proposições podem ter no contexto do cotidiano e não como propostas que visem delimitar o trabalho coletivo. Em outras palavras, reconhece-se que a negociação não pode ser tratada como uma ação que ignore as expectativas envolvidas e que nem sempre condizem com o mundo vivido, com a realidade vivenciada.

\section{CONSIDERACְÕES FINAIS}

Snow (1993) indicou que há uma separação entre culturas em nossa sociedade que perpetua desentendimentos e equívocos, gerando, em muitos casos uma visão de ciência que nem sempre condiz com a realidade. Ela reside em um tipo de afastamento que não pode ser compreendido como mero desprendimento do real, mas como um jogo social complexo (BOURDIEU, 2003). Para Grillo (2013) esse jogo entre campo científico e o mundo externo a ele refletindo na divulgação científica de diferentes formas de seu uso e produção. Partindo desse pressuposto que o presente trabalho busca a defesa pela constituição da divulgação científica como espaço de criação coletiva e aproximação entre campos, assim, percebendo a necessidade de compreender, inicialmente, a motivação provinda de uma divulgação científica produzida por um espaço intelectual específico.

Essa relação existente entre divulgação científica e o campo científico, pode, então, ser mais bem compreendida através da ideia de fronteira. Pensar na relação de aproximação entre diferentes campos requer reconhecer que existe o campo científico e o mundo escolar (e tantos outros que se possa defender) onde a DC pode se construir e estruturar. Nesse aspecto é o campo científico o espaço social que possui uma estrutura mais ou menos sedimentada e cuja função é perpetuar as posições de poder e a lógica das trocas simbólicas específicas da ciência (BOURDIEU, 2010). Esse lugar reflete, em grande parte, os conhecimentos que estão sendo apresentados e que estão sendo regulados pelos seus agentes.

Por isso, ao defender que a fronteira é o lugar de encontro entre espaços sociais, cujo valor simbólico trazido dos campos de origem pode ganhar outros sentidos, negociados entre os agentes sociais, podendo colocar em pauta os elementos mascarados pelo jogo de regulação que deve ou não ser apresentado ao público (GRILLO, 2013).

Assim, futuros estudos sobre o capital simbólico será um dos elementos tratados para compreender essa negociação e troca valiosa na fronteira, pois é dele e da aproximação com os outros capitais simbólicos provindos de outros mundos sociais, que insurge na reflexão e na ação, questionamentos e conflitos que podem caracterizar o novo.

Para que isso seja possível, ou seja, o que chamamos de reflexividade como ação criativa, é necessário discutir a divulgação científica como instrumento de superação da alienação. Entende-se, inicialmente, que esse discurso surge da reflexão pautada nos saberes sociológicos conforme percebidos pelos trabalhos tratados anteriormente. Isso reflete um dos pilares das reflexões sociais acerca 
da dimensão crítica sobre o mundo vivido e na condição de promoção dos questionamentos que superem a aceitação acrítica da realidade vivenciada.

Essa dimensão reconhece na ciência um dos instrumentos que possibilita o desvelamento do senso comum, como elemento reflexivo e que pode desvencilhar os discursos alienantes amparados no saber científico (GERMANO; KULESZA, 2007). O encontro da ciência e o descortinar dos jogos de poder, assim, encontram na divulgação científica um espaço importante para superação dessas dimensões. A perspectiva da fronteira, portanto, parece-nos permitir colocar em debate o papel da ciência na sociedade, defendendo a construção de um discurso que possa apontar caminhos, trazer reflexões e ponderações onde o saber científico pode ser estruturante dos questionamentos e não somente ponto de partida ou objetivo.

Nesse olhar, também, é possível compreender os arquétipos que são produzidos pela divulgação científica (PECHULA, 2007), visto que é na aproximação com o outro, que se percebe as diferenças e equívocos. Deste modo, permite entender como a ciência possui o interesse de representar seus agentes, em geral, destituídos de desejos próprios. Confronta também a mídia que, por sua vez, reforça o imaginário social da ciência como instituição neutra e os cientistas como detentores do conhecimento universal, ao mesmo tempo em que descaracteriza o campo científico, tratando temáticas marginais da ciência como saberes reconhecidos no campo. Compreender os capitais simbólicos e a divulgação científica produzida na interação entre diferentes mundos pode trazer aos desvelamentos das tensões que são menos aparentes, onde existem de modo implícito as diferenças sociais. Em outras palavras, é preciso mobilizar novos olhares para compreender como esses instrumentos estão sendo negociados e tratados de modo a enfrentar essa problemática.

O saber científico adaptado ao discurso para o público leigo e escolar, também pode, na divulgação científica, ser um instrumento educacional relevante (DIAS; ALMEIDA, 2010; SILVA; KAWAMURA, 2001). Nesse espaço que se pensa sobre as especificidades da escola e como os discursos científicos podem ganhar sentidos pedagógicos para a formação dos alunos, construindo uma relação entre ciência e divulgação científica na perspectiva educacional. Por tal motivo, a fronteira pode ser fundamental para permitir o acesso de diferentes mundos e, a divulgação científica, se torna não somente o elo entre dois lugares (científico e escolar), mas o lugar que cria e adapta os discursos levando em conta todos os problemas, peculiaridades e potencialidades que deles emergem.

Em suma, nesse trabalho, pode-se reconhecer que há indícios de que tratar a divulgação científica como espaço de criação na fronteira e como atividade provinda da fronteira, nos permite fugir das armadilhas conceituais que a estruturam e delimitam em demasia (JACOBI; SCHIELE, 1988). Desse modo, é importante reconhecê-la como o lugar criativo e em constante mobilidade, capaz de absorver diferentes reflexões, culturas, perspectivas, problemas, fazendo-a, por ora, o lugar de construção coletiva que evoca mudanças e evita equívocos.

Portanto, a divulgação científica enquanto processo constituído na fronteira pode possibilitar dar um passo além nos debates conceituais para entender como menos flutuante, pairando sobre diferentes campos (BEAUNE, 1988), mas também como menos estruturada, sem perspectiva de mudança e 
mobilidade (MACHADO; CONDE, 1989): ela pode ser o lugar do coletivo, sem a necessidade de denominação ou conceito que possa dar conta de um instrumento intelectual reflexivo e prático tão complexo.

\section{REFERÊNCIAS}

ÁGUAS, C. L. P. A tripla face da fronteira: reflexões sobre o dinamismo das relações fronteiriças a partir de três modelos de análise. Fórum Sociológico, v. 23, n. 23, p.1-12, 2013.

BEAUNE, J.-C. La vulgarisation scientifique: l'ombre des techniques. In: JACOBI, D.; SCHIELE, B. Vulgariser la science: le procès de l'ignorance. $1^{\text {a }}$ ed. Seyssel: Champs Vallon, v. 1, p. 47-81, 1988.

BARDIN, L. Análise de conteúdo. $1^{\text {a }}$ ed. Lisboa: Edições 70, 1977.

BOURDIEU, P. Razões práticas. Sobre a teoria da ação. 11ª Ed. Campinas: Papirus, 1996. 224 p.

BOURDIEU, P. O campo científico. In: ORTIZ, R. A sociologia de Pierre Bourdieu. $1^{\text {a }}$ Ed. São Paulo: Olho d’Água, 2003. Cap. 4, p. 112-143.

BOURDIEU, P.. O poder simbólico. 14 ${ }^{a}$ Ed. Rio de Janeiro: Bertrand, 2010.

BOURDIEU, R., CHAMBOREDON, J.C., PASSERON, J.C. O ofício do sociólogo. Metodologia da pesquisa na sociologia. Rio de Janeiro: Vozes, 2015.

CARDOSO, D.; NORONHA, A.; WATANABE, G.; GURGEL, I. Texto jornalístico sobre ciência: uma análise do discurso sobre a natureza da ciência. Alexandria - Revista de Educação em Ciência e Tecnologia, v. 8, n. 3, p. 229-251, 2015.

DAVIS, J. P.; BELLOCCHI, A. Objectivity, subjectivity, and emotion in school science inquiry. Journal Research Science Teaching, v. 55, p. 1419-1447, 2018.

DESCHAMPS, J. Communicational Mediations. In: DESCHAMPS, J. (Ed.) Mediation. $1^{\mathrm{a}}$ ed. Londres: Wiley, 2019.

DIAS, R. H. A.; ALMEIDA, M. J. P. M. D. A Repetição em Interpretações de Licenciandos em Física ao Lerem as Revistas Ciência Hoje e Pesquisa Fapesp. Ensaio - Pesquisa em Educação em Ciências, v. 12, n. 3, p. 51-64, 2010.

DIXON, B. Packaging science for a reference series. International Journal of Science Education, Inglaterra, v. 13, n. 5, p. 583-587, 1991.

FERREIRA, L. N. D. A.; QUEIROZ, S. L. Textos de divulgação científica no ensino de ciências: uma revisão. Alexandria, v. 5, n. 1, p. 3-31, maio, 2012.

GERMANO, M. G.; KULESZA, W. A. Popularização da Ciência: uma Revisão Conceitual. Caderno Brasileiro de Ensino de Física, v. 24, n. 1, p. 7-25, 2007.

GRILLO, S. V. C. Divulgação científica: linguagens, esferas e gêneros. Tese (Livre Docência em Filologia e Língua Portuguesa) - Faculdade de Filosofia, Letras e Ciências Humanas, Universidade de São Paulo, São Paulo, 2013.

JACOBI, D.; SCHIELE, B. Vulgariser la science: le procès de l'ignorance. Syssel: Champ Vallon, 1988. 
KELSEY, E. Conceptual change and killer whales: constructing ecological values for animals at the Vancouver Aquarium. International Journal of Science Education,

Inglaterra, v. 13, n. 5, p. 551-559, 1991.

KINGSLAND, R. Science clubs - the extra dimension. International Journal of Science Education, Inglaterra, v. 13, n. 5, p. 589 - 596, 1991.

LANGAN, L. M., CHENG, Y., HUNKA, A. D. Empirically supported out-of-the-box strategies for science communication by environmental scientists. Integrated Environmental Assessment and Management, Accepted Author Manuscript, 2019.

LIMA, G. S.; GIORDAN, M. O movimento docente para o uso da divulgação científica em sala de aula: um modelo a partir da Teoria da Atividade. Revista Brasileira de Pesquisa em Educação em Ciências, v. 18, n. 2, p. 493-520, 2018.

LOPES, J. T. Sociabilidade e consumos culturais: contributos para uma sociologia da fruição cultural. $1^{\circ}$ Congresso Português de Sociologia Econômica. Lisboa, 1998. p. 179-188.

MACHADO, F. L.; CONDE, I. Públicos da divulgação: imagens e sociografia. Revista Sociologia, n. 6, p. 81-100, 1989 .

MADDOCK, M. Education, research and passive recreation: an integrated programme at the Wetlands Centre, Shortland. International Journal of Science Education, Inglaterra, v. 13, n. 5, p. 561-568, 1991.

MARTINS, I.; NASCIMENTO, T. G.; ABREU, T. B. Clonagem na sala de aula: um exemplo do uso didático de um texto de divulgação científica. Investigações em Ensino de Ciências, v. 9, n. 1, p. 95-111, 2004.

MARTINS, J. D. S. O tempo da fronteira. Retorno à controvérsia sobre o tempo histórico da frente de expansão e da frente pioneira. Tempo Social, São Paulo, v. 8, n. 1, p. 25-70, maio, 1996.

MARTINS, R. C. O paradoxo da demarcação emancipatória: a fronteira na era da sua reprodutibilidade icônica. Revista Crítica de Ciências Sociais, n. 59, p. 37-63, fevereiro, 2001.

MAY, S. Case Studies. In: SCOTT, C.R.; BARKER, J.R.; KHUN, J.; KEYTON, J.; TURNER, P.K.; LEWIS, L. K. (ed.) The International Encyclopedia of Organizational Communication, 2017.

NASCIMENTO, T. G.; REZENDE, M. Produção sobre divulgação científica na área de educação em ciências: referenciais teóricos e principais temáticas. Investigações em Ensino de Ciências, v. 15, n. 1, p. 97-120, 2010.

PECHULA, M. R. A Ciência nos Meios de Comunicação de Massa: Divulgação de Conhecimento ou Reforço do Imaginário Social. Ciência \& Educação, v. 13, n. 2, p. 211-222, 2007.

PRICE, S.; HEIN, G. E. More than a field trip: scienc programmes for elementary school group at museum. International Journal of Science Education, Inglaterra, v. 13, n. 5, p. 505-519, 1991.

RIBEIRO, A. S. A retórica dos limites. Notas sobre o conceito de fronteira. In: SANTOS, B. D. S. A globalização e as ciências sociais. São Paulo: Cortez, v. 1, 2005. Cap. 12, p. 475-501.

RIBEIRO, R. A.; KAWAMURA, M. R. D. Divulgação científica e ensino de física: intenções, funções e vertentes. In: Atas do X Encontro de Pesquisa em Ensino de Física, Londrina: Sociedade Brasileira de Física, 2006 (online). 
RIBEIRO, R. A. Divulgação científica e ensino de física: intenções, funções e vertentes. Dissertação (Mestrado em Ensino de Ciências) - Instituto de Física, Universidade de São Paulo, 2007.

SCHNEIDER, E. M.; MEGLHIORATTI; F. A.; SOARES, A. S. F. Reflexões de um grupo de professores acerca do melhoramento genético humano a partir de discussão de textos de divulgação científica. Ensaio Pesquisa em Educação em Ciências, v, 19, e2848, 2017.

SILVA, H. S.; ALMEIDA, M. J. P. M. O deslocamento de aspectos do funcionamento do discurso pedagógico pela leitura de textos de divulgação científica em aulas de física. Revista Electrónica de Enseñanza de las Ciencias, v. 4, n. 3, p. 1-25, 2005.

SILVA, J. A. D.; KAWAMURA, M. R. D. A Natureza da Luz: uma Atividade com Textos de Divulgação Científica em Sala de Aula. Caderno Catarinense de Ensino de Física, v. 18, n. 3, p. 317-339, 2001.

SILVERMAN, D. Interpretação de Dados Qualitativos: Métodos para Análise de Entrevistas, Textos e Interações. São Paulo: Artmed, 2009. 376 p.

SNOW, C. P. As duas culturas e um segundo olhar. São Paulo: Editora USP, 1993.

SOUZA, I. M. D. A.; CAITITÉ, A. M. L. A Incrível História da Fraude dos Embriões Clonados e o que ela nos diz sobre Ciência, Tecnologia e Mídia. História, Ciências, Saúde, Manguinhos, v. 17, n. 2, p. 471-493, 2010.

SOUZA, P. H. R.; ROCHA, M. B. O caráter híbrido dos textos de divulgação científica inseridos em livros didáticos. Ciência \& Educação, v. 24, n. 4, p. 1043-1063, 2018.

SUGIMOTO, C.R.; WORK, S.; LARIVIÈRE, V.; HAUSTEIN, S. Scholarly use of social media and alt metrics: a review of the literature. Journal of the association for information science and technology, v. 68, p. 2037-2062, 2017.

STEVENSON, J. The long-term impact of interactive exhibits. International Journal of Science Education, Inglaterra, v. 13, n. 5, p. 521-531, 1991.

WATANABE, G; KAWAMURA, M.R. Um sentido social para a divulgação científica: perspectiva educacionais em visitas a laboratório científicos. Alexandria - Revista de Educação em Ciências e Tecnologia, v. 8, n. 1, p. 209-235, 2015.

WATANABE, G; KAWAMURA, M.R. El papel de la divulgácion científica realizada por científicos en la formación de profesores. Revista Eletrónica Interuniversitaria de Formación del Profesorado, v. 19, n. 2, p. 61-73, 2016.

WILKIE, T. Does science get the present it deserves? International Journal of Science Education, Inglaterra, v. 13, n. 5, p. $575-581,1991$.

\section{NOTAS}

1 É importante salientar que na teoria de Pierre Bourdieu a constituição de campo se dá através de diferentes critérios que perpassam por organizações seculares e processos de autonomia que precisam ser colocadas em xeque ao longo de períodos substanciais de tempo e historicidade. Portanto, nesse trabalho, pretende-se utilizar o termo "espaço social" em detrimento de campo nas situações em que não se tem confirmações teóricas e práticas da constituição de campo sociais como no caso da escola. Cabe, contudo, salientar, que a escola pode ser compreendida como campo 
ainda que o presente trabalho não possui dados efetivos para fazer essa afirmação categórica. Campo científico, por sua vez, já foi trabalhado em diferentes livros e artigos de Pierre Bourdieu como "Science de la Science e réflexivité" de 2001.

Submetido em 06/09/2018

Aprovado em 27/06/2019

\section{Contato:}

Rua Av. dos Estados, 5001 Bairro Bangú

CEP 09.210-580 - Santo André - SP

\section{ERRATA}

DOI: http://doi.org/10.1590/1983-21172020210118

No artigo: WATANABE, GRACIELLA; MUNHOZ, MARCELO GAMEIRO; KAWAMURA, MARIA REGINA. CONTRIBUIÇÕES DA SOCIOLOGIA PARA O ESTUDO DA DIVULGAÇÃO CIENTÍFICA NA INTERFACE CAMPO CIENTÍFICO E ESPAÇO ESCOLAR: UM OLHAR A PARTIR DO CONCEITO DE FRONTEIRA. Ens. Pesqui. Educ. Ciênc. (Belo Horizonte), Belo Horizonte, v. 21, e10581, 2019. Available from <http://www. scielo.br/scielo.php?script $=$ sci_arttext\&pid $=$ S1983-21172019000100321\&lng $=$ en\&nrm=iso $>$. access on 23 Apr. 2020. Epub Nov 25, 2019. https://doi. org/10.1590/1983-21172019210122, na página 4, $3^{\circ}$ parágrafo, $5^{a}$ linha,

Onde se lia:

Stevenson (1991) apresentou uma pesquisa interessante sobre o impacto à longo prazo com 79 adultos e crianças que participavam de uma visita ao.

\section{Leia-se:}

Stevenson (1991) apresentou uma pesquisa interessante sobre o impacto à longo prazo com 79 adultos e crianças que participavam de uma visita ao London's Science Museum. 